\title{
Bonnat, Le Bourg-d'Hem, Linard
}

\section{Christine Serre}

\section{OpenEdition \\ Journals}

Édition électronique

URL : http://journals.openedition.org/adlfi/7901

ISSN : 2114-0502

Éditeur

Ministère de la culture

Référence électronique

Christine Serre, «Bonnat, Le Bourg-d'Hem, Linard», ADLFI. Archéologie de la France - Informations [En ligne], Limousin, mis en ligne le 01 mars 2005, consulté le 19 avril 2019. URL : http:// journals.openedition.org/adlfi/7901

Ce document a été généré automatiquement le 19 avril 2019

(c) Ministère de la Culture et de la Communication, CNRS 


\title{
Bonnat, Le Bourg-d'Hem, Linard
}

\author{
Christine Serre
}

Identifiant de l'opération archéologique : 122354

Date de l'opération : 2005 (PR)

Deux communes ont été essentiellement prospectées cette année. Tout d'abord, Le Bourgd'Hem. Le territoire avait été prospecté en 2000 ; le travail a donc consisté en une vérification des fiches établies à l'époque, ainsi qu'un éventuel complément d'information. Ont ainsi été complétées une fiche sur le château de Villebaston, ainsi qu'une autre sur une villagallo-romaine se trouvant au lieu-dit « Le Guémontet ». Lors de la prospection dans ce dernier village, un morceau de colonne inédit provenant sans doute du site a été retrouvé. L'emplacement de la chapelle du Temple est également repéré, malheureusement, il n'en reste aucune trace. Concernant cette chapelle, il est possible qu'une confusion ait lieu depuis longtemps: en effet, elle est parfois appelée «chapelle du Temple de Villard», prenant ainsi le nom du bois qui se trouve à l'est du village du Temple.

2 Il existe cependant une autre chapelle se trouvant aux environs de Dun-le-Palestel, au village du Villars. Elle est attestée, par l'abbé Lecler et Ambroise Tardieu, sous le nom de «Temple de Villars». Y aurait-il eu amalgame? La chapelle du Bourg-d'Hem semblait dépendre de la commanderie de la Forêt du Temple. Celle de Villars de la commanderie de Viviers.

3 En ce qui concerne la commune de Linard, 9 fiches ont été établies. Quatre concernent de l'outillage lithique retrouvé sur quelques parcelles du village de «La Cartelade ». Ont été découvertes des haches polies du Néolithique, mais surtout des racloirs, grattoirs, pointes de type moustérien. Lors de la prospection au sol, deux autres silex taillés ont été trouvés. $\mathrm{Au}$ vu du nombre de pièces, il devait s'agir d'un emplacement régulièrement fréquenté, et ce pendant une période assez longue. L'endroit se trouve en contre-haut par rapport à la Petite Creuse, et présente d'autant plus d'intérêt que l'on trouve peu de Moustérien dans cette région. Entre la rivière et le site paléolithique se trouve une villagallo-romaine qui sera prospectée l'année prochaine. De même, une villaa été découverte au village 
de Nioux. Des poteries et des tegulaeont été retrouvées. L'année 2006 nous permettra d'en savoir un peu plus. Enfin, une amulette en terre cuite a été retrouvée dans un jardin de Guéret, et fait l'objet d'une fiche, bien que ne faisant pas partie du territoire de prospection.

INDEX

Index chronologique : Néolithique

Index géographique : Limousin, Creuse (23), Bonnat

operation Prospection (PR)

Thèmes : chapelle, château, colonne, grattoir, hache polie, industrie lithique, racloir, tuile, villa peuple Moustérien

\section{AUTEURS}

CHRISTINE SERRE

BEN 